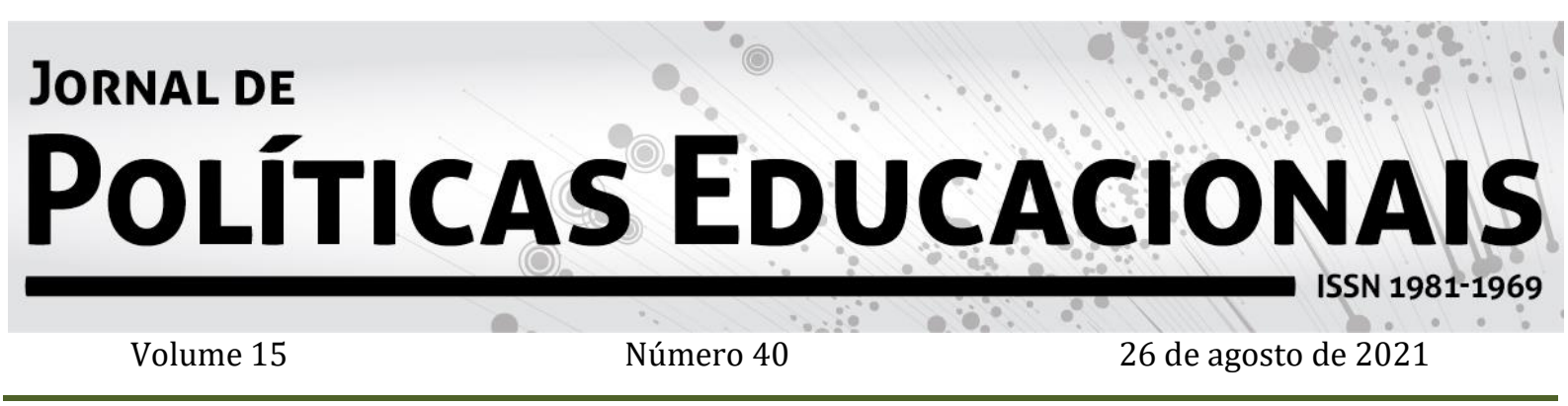

\title{
As Transformações do Sistema Educacional do Chile: a parceria público-privada e a privatização dos recursos
}

\section{Changes in Chilean Education System: public private partnership and privatization of resources}

\section{Las transformaciones del Sistema Educacional de Chile: convenios público privados y la privatización de recursos}

\author{
Maria Otília Kroeff Susin ${ }^{1}$ \\ Juliana Mendonça²
}

Citação: SUSIN, M.O.K; MENDONÇA, J. As Transformações do Sistema Educacional do Chile: a parceria público-privada e a privatização dos recursos. Jornal de Políticas Educacionais. V. 15 n. 40. Agosto de 2021.

http://10.5380/ipe.v15i0.79391

\begin{abstract}
Resumo: 0 objetivo central deste texto é mostrar como se desenvolveu o processo de privatização da educação pública no Chile, engendrado desde os tempos do regime militar, período em que foi imposto um programa de reformas políticas de vertente neoliberal, que estabeleceu uma economia de livre mercado, na qual sujeitos privados passaram a intervir na esfera pública. Após a ditadura, as lutas dos movimentos estudantis, aliadas a uma legislação permeada de avanços e retrocessos, são elementos que dão forma ao Sistema Nacional de Educação chileno. A presença do setor privado no direcionamento das políticas públicas e nas parcerias com o Estado passam a ser constantes dentro e fora das escolas. Nesse contexto, de múltiplos sujeitos atuando de diferentes formas, muitos deles dependentes de subsídios estatais, busca-se investigar quem são e como agem, não no sentido de exaurir a pesquisa, mas de tentar encontrar, por meio de alguns exemplos, respostas para os problemas dessa pauta privatizadora. Pretende-se discutir, ainda, sobre a configuração dessa lógica de mercado na educação do Chile que, somada a fatores da economia neoliberal, levou o país a uma crise de âmbito político-democrático, eclodida em 2019, na qual cidadãos
\end{abstract}

\footnotetext{
${ }^{1}$ Doutora em Educação. Professora aposentada da Secretaria Municipal de Educação de Porto Alegre/RS. Pesquisadora do Grupo de Pesquisa Relações entre o Público e o Privado na Educação (GPRPPE) da Faculdade de Educação da Universidade Federal do Rio Grande do Sul/UFRGS. Porto Alegre. Rio Grande do Sul. Brasil. Orcid: https://orcid.org/0000-0002-2361-502X. E-mail: otiliasusin@gmail.com

${ }^{2}$ Graduanda em Filosofia pela Universidade Federal do Rio Grande do Sul (UFRGS). Integrante do Grupo de Pesquisa Relações entre o Público e o Privado na Educação (GPRPPE) da Faculdade de Educação da Universidade Federal do Rio Grande do Sul/UFRGS. Porto Alegre. Rio Grande do Sul. Brasil. Orcid: https://orcid.org/0000-0003-1144-0901. E-mail: julismendonca@gmail.com
} 


\title{
JORNAL DE Políticas EducacionaIS \\ ISSN 1981-1969
}

chilenos pleiteiam direitos e acesso igualitário a uma educação de qualidade para as diferentes classes sociais.

Palavras-chave: Educação, Chile, Parceria Público-Privada.

\begin{abstract}
The main objective of the text is showing how the process of privatization in Chile's public education has been developed, engendered since times of military regime, when a program of political reforms with neo-liberal components was enforced, establishing a free market economy, in which private subjects became actively involved in the public sphere. After dictatorship, the struggles of student's movements, combined with a legislation permeated by both progress and retreats, are elements that give shape to the Chilean National Education System. The presence of the private sector in the direction of public policies, as well as in partnerships with the State became a constant, either inside and outside schools. In this context of multiple subjects acting in different ways, many of them reliant on state subsidies, we pursue to investigate who they are and how they act, in order not to exhaust our research, but to try to find, by a few examples, some answers for several privatization issues. We intend to discuss, yet, how this market logic in Chile's education, allied to neo-liberal economic factors, led the country to a political-democratic crisis, erupted in 2019, in which Chileans citizens claim for civil rights and for equal access to a quality education for all different social classes.
\end{abstract}

Keywords: Education, Chile, Public Private Partnership.

Resumen: El objetivo central de este texto, es mostrar cómo se desarrolló el proceso de privatización de la educación pública en Chile, gestado desde los tiempos del régimen militar, periodo en el que fue impuesto un programa de reformas políticas de cuño neoliberal que estableció una economía de libre mercado, en la cual sujetos privados pasaron a intervenir en la esfera pública. Después de la dictadura, la lucha de los movimientos estudiantiles aliada a una legislación permeada por avances y retrocesos, va dando forma al Sistema Nacional de Educación Chileno. La presencia del sector privado en el direccionamiento de las políticas públicas y en convenios con el estado, pasa a ser una constante dentro y fuera de las escuelas. En este contexto de múltiples sujetos actuando de diferentes formas, muchos de ellos dependiendo de subsidios estatales, se busca investigar quienes son y cómo actúan, no en el sentido de agotar la investigación y sí de tentar encontrar, a través de algunos ejemplos, respuestas para esta agenda privatizadora. Se pretende discutir todavía, sobre la configuración de esta lógica de mercado en la educación en Chile, que sumada a factores de la economía neoliberal, llevó al país a una crisis de ámbito político democrático, estallada en 2019, en la cual, ciudadanos chilenos pleitean derechos y acceso igualitario a una educación de calidad para diferentes clases sociales.

Palabras clave: Educación, Chile, Convenio Público Privado.

\section{Introdução}

Este artigo apresenta os principais achados da investigação realizada a partir de 2016, sobre o processo de privatização da educação pública no Chile, um dos países que, juntamente com a Argentina, a Bolívia, o Brasil, o Uruguai e a Venezuela, faz parte da pesquisa: Implicações da relação público-privado para a democratização da educação na América Latina. Esta é desenvolvida pelo Grupo de Pesquisa Relações entre o Público e o Privado na Educação (GPRPPE), coordenado pela Dr. - Vera Maria Vidal Peroni e faz parte 


\section{JORNAL DE Políticas Educacionals}

ISSN 1981-1969

do Núcleo de Política e Gestão da Educação da Universidade Federal do Rio Grande do Sul (UFRGS).

O conceito de democracia que orienta nossas análises está ancorado em Wood (2003), quando afirma a materialização de direitos e de igualdade social, direitos estes consubstanciados em políticas públicas, que no caso da educação se dá em escola pública e de qualidade para todas as crianças. Essas políticas devem ser fruto de decisões coletivas, com efetiva participação na sua elaboração, segundo Vieira (1998) e, ainda, Mészáros (2002), que afirma a necessidade do efetivo acompanhamento e da avaliação dessas políticas por meio de uma prática social crítica e autocrítica, no curso de seu desenvolvimento.

O estudo se organizou inicialmente pela análise do período da história chilena estabelecido entre 1973 e o tempo presente, recorte que se mostra significativo ao exame do modo como se deu a transformação da educação estatal, no decorrer de quase 50 anos. Um olhar atento à formação histórico-política do Chile se justifica na tentativa de compreender os problemas que permeiam o modelo de privatização do sistema de educação naquele país.

Com base nesse diálogo com a história, a segunda parte da nossa pesquisa intencionou sondar como se estabelecem as parcerias entre o público e o privado, no âmbito da educação, de forma a identificar quem são e como agem alguns dos principais sujeitos privados que atuam na educação chilena e que se autointitulam representantes da sociedade civil. Tais sujeitos aparecem organizados em rede ou de forma individual, recebem subsídios públicos e atuam na definição das políticas educacionais, apontando a ineficiência do Estado.

Nas considerações finais, pretendemos sustentar que o modelo de educação chileno, voltado à privatização do ensino público e à livre concorrência entre escolas, defendido como forma de aumentar a qualidade da educação, fracassou. Prova disso é a flagrante desigualdade entre a educação destinada aos ricos e àquela relegada aos pobres. No recente levante popular, que culminou na aprovação, por meio de um plebiscito, da 


\section{JORNAL DE} Políticas EducacionaIS

ISSN 1981-1969

criação de uma nova Constituição, as demandas por uma educação mais democrática são prementes. A atual Carta data do período ditatorial de Augusto Pinochet.

Quanto ao enfoque metodológico, a pesquisa desenvolveu-se pela conjugação de um aporte teórico (base de muitos conceitos utilizados), interlocução com pesquisadores chilenos e fontes documentais das instituições privadas investigadas, disponíveis em páginas na Internet.

Assim, as linhas seguintes deste texto revelam a tentativa de melhor compreender como se materializa a relação entre o público e o privado na educação no Chile e as implicações do modelo de privatização da educação para a democracia, considerando as especificidades de cada país, bem como o momento atual, especialmente ante a crise política de outubro de 2019, que demonstrou fissuras no modelo econômico assumido pelo Chile nos anos posteriores à ditadura militar.

\section{o Período Pinochet e o Desmonte do Estado Democrático: o que aconteceu com a Educação?}

As heranças deixadas pelo passado ditatorial recente do Chile marcaram a sociedade com uma experiência violenta de perseguições, desaparecimentos e mortes de muitos/as chilenos/as, gerando insegurança e medo, pois "[...] bastava os militares ameaçarem que iam aquartelar-se para ver a impressão que causavam. Não precisavam agir, bastava aquartelar-se" (SANTA CRUZ, 2016, entrevista, tradução nossa) 3. Ou seja, ameaças já eram suficientes para frear qualquer tentativa de oposicionistas aos ditames do governo militar.

Essa herança também nos faz compreender como se constituíram as concepções políticas impregnadas na sociedade chilena, cujo período da ditadura militar de Augusto Pinochet (1973/1990) representou "[...] uma das mais radicais experiências em matéria de política educacional no mundo", orientando o funcionamento do sistema educacional

\footnotetext{
3 Eduardo Santa Cruz, sociólogo, professor, pesquisador e doutor do Centro de Investigação da Universidade do Chile. Entrevista realizada em Santiago/Chile, 2016.
} 


\section{JORNAL DE}

\section{POLÍTICAS EDUCACIONAIS}

ISSN 1981-1969

"na lógica do mercado, terminando com o Estado Docente" (BELLEI, 2016, entrevista, tradução nossa) ${ }^{4}$.

O Chile, com o regime militar, foi pioneiro na implantação do neoliberalismo, sendo considerado como o "Laboratório do Neoliberalismo" na América Latina. A sociedade chilena, segundo Orellana (2020), com esse modelo criou um crescimento econômico importante do qual se apropriou uma diminuta elite - $1 \%$ da sociedade chilena concentra 33\% da riqueza produzida no país (ORELLANA, 2020, informação verbal, tradução nossa) ${ }^{5}$. A privatização das riquezas naturais chilenas foi outra prática instituída ao longo dos anos da ditadura, atingindo o cobre, sua principal riqueza, e a privatização da água, por meio do Código das Águas aprovado em 1981. Mesmo passados 30 anos do fim da ditadura militar, esse processo de privatização não foi revertido. Segundo Orellana (2019), “A economia neoliberal chilena é muito concentrada em atividades principalmente extrativista e de serviços de baixa agregação de valor. É um neoliberalismo latino-americano, em resumo" (ORELLANA, 2019, tradução nossa).

Orellana (2020), ao analisar o processo chileno que levou ao plebiscito para a elaboração de uma nova Constituição, afirma que esse processo é protagonizado por um novo sujeito, que se engendrou no interior do neoliberalismo, o qual gerou uma nova sociedade de trabalhadores de serviços (ORELLANA, 2020, informação verbal, tradução nossa). Portanto, do movimento de 18/10/2019 até o movimento do plebiscito em $25 / 10 / 2020$, protagonizado também pelos estudantes, há uma grande maioria social que se manifesta contra o modelo neoliberal chileno. 0 que o povo expressa com esses intensos movimentos é "[...] um fenômeno político com demandas sociais, demandas populares contra a tremenda mercantilização da vida que não estão sendo escutadas e que não foram ouvidas por décadas" (ORELLANA, 2020, informação verbal, tradução nossa).

\footnotetext{
${ }^{4}$ Cristian Bellei Carvacho é pesquisador em Educação da Universidade de Chile e na faculdade de Ciências Sociais no curso de Sociologia. Entrevista realizada em Santiago/Chile, 2016.

${ }^{5}$ Victor Orellana na Live Diálogos entre o Público e o Privado/GPRPPE, realizada em 09 de novembro de 2020, reproduzida no canal YouTube. Disponível em: https://www.youtube.com/c/GPRPPEUFRGS/featured. Acesso em: 22 jan. 2021.
} 


\section{JORNAL DE}

\section{Políticas Educacionals}

ISSN 1981-1969

A vitória que representou o plebiscito significa uma Assembleia Constituinte paritária, entre homens e mulheres, pela primeira vez na história do Chile. E, para Orellana (2020, informação verbal, tradução nossa), “[...] a disputa nesse processo constituinte pode ser a manipulação, mais uma vez, das ignorâncias populares ou iniciar um ciclo de transformações de saída do neoliberalismo". Apostamos nessa segunda hipótese.

No modelo econômico chileno, a segregação dos mais pobres deixa-se mostrar com muita ênfase em um sistema educacional que privilegia as famílias com maiores rendas. As chances de uma boa formação não estão no horizonte de uma parcela da sociedade, porque existe uma desigualdade de natureza estrutural no Chile (AHUMADA, 2020, tradução nossa). A educação chilena, antes da ditadura militar, desenvolvia-se por meio de um sistema misto, no qual coexistiam a educação pública e a privada, sendo que esta sempre se caracterizou como uma colaboradora do Estado na educação legal, fundamentalmente provida pela Igreja Católica e suas congregações. 0 Estado Docente no Chile consolidou-se na segunda metade do século XIX, quando o Estado criava, administrava e provia de forma centralizada, por meio do Ministério da Educação e seus escritórios, o sistema administrativo público. A educação privada no Chile abarcava inicialmente escolas mantidas pela Igreja, surgindo após as fundações sem fins lucrativos, fundações beneficentes mais tradicionais e também escolas culturais das colônias de imigrantes ingleses, alemães, italianos e franceses. Segundo Bellei (2015), a primazia da educação chilena era pública, com interveniência do Estado, que era o financiador da educação pública.

O autor Xavier Vanni (2015), no texto Evolución de las políticas educacionales em Chile: 1980-2004, analisa a reforma educacional levada a efeito por Pinochet, elencando quatro iniciativas, cuja primeira foi terminar com a oferta da educação pelo Estado Nacional, repassando a responsabilidade para os municípios. Tal municipalização da educação consistiu na descentralização da oferta bem como da responsabilização da municipalidade pelos custos, sem, contudo, descentralizar recursos. No Chile, não existem recursos públicos com vinculação específica para a educação. 


\section{JORNAL DE}

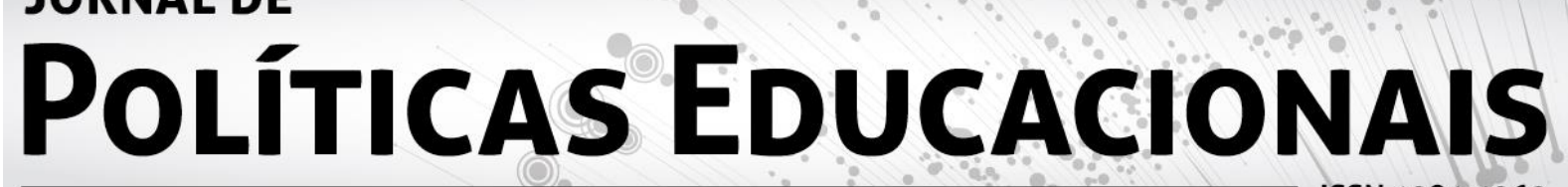

A segunda iniciativa do governo militar foi expandir a participação da iniciativa privada na educação por meio de pessoas individuais ou instituições com e sem fins lucrativos, que passaram a receber recursos públicos. A terceira foi instituir a competição entre as escolas para captar a preferência das famílias, criando o financiamento via vaucher. Cada aluno representava um valor que seria repassado à escola, mediante a comprovação de matrícula e de frequência. Em quarto lugar, o autor coloca a desregulamentação da carreira dos docentes, acabando com as leis trabalhistas e os direitos adquiridos pelos professores chilenos (VANNI, 2015, p. 24, tradução nossa).

Corroborando as palavras de Santa Cruz (2016), Vanni (2015) afirma que essa revolução, que preferimos caracterizar como destruição no sistema educacional chileno, só foi possível devido às excepcionais condições que a ditadura militar impôs ao Chile.

O sistema educacional chileno era considerado um sistema misto, no qual conviviam escolas municipalizadas, que em 1981 foram assumidas administrativa e financeiramente pelas prefeituras; as escolas subvencionadas, que eram particulares e recebiam recursos do Estado, podendo ainda cobrar um valor das famílias, chamado de copago; e as escolas particulares, inteiramente pagas pelas famílias e que não recebiam recursos públicos.

Segundo Ruiz e Boccardo (2014), o papel da municipalização da educação no Chile foi no mínimo controverso, uma vez que transferiu as funções do governo central para as prefeituras sem que tivessem estrutura técnica e financeira para essa responsabilidade e principalmente por considerar tal medida como parte de um "projeto de modernização" do país e da educação, projeto esse que foi aplicado de forma coercitiva pelo governo militar. A municipalização foi extremamente prejudicial aos professores, que tiveram a perda de todos direitos já incorporados nas suas carreiras ao passarem a atuar nas escolas municipalizadas. "Los profesores de instituciones estatales quedan regidos por la legislación laboral del sector privado, lo que merma la proyección de sus remuneraciones y su estabilidad laboral" (RUIZ; BOCCARDO, 2014, p. 21).

0 regime militar instituiu, na educação chilena, um formato bastante privatizado que se materializa pela implementação de muitas reformas impostas ao longo de 17 anos, 


\section{JORNAL DE Políticas EducacionaIS} ISSN 1981-1969

implodindo conquistas remanescentes ao período de Salvador Allende, como foi o caso do fim da gratuidade no ensino superior em 1981, que era um direito assegurado a todos os estudantes.

\section{A Educação no Período Pós-Ditadura no Chile}

A privatização da educação chilena, herança do período militar, está expressa nos números que indicam a distribuição das 3.582.353(três milhões, quinhentos e oitenta e dois mil e trezentos e cinquenta e três) matrículas pelo universo de escolas, quais sejam: $34,1 \%$ em escolas públicas, 53,9\% nas escolas particulares subvencionadas e 9,2\% nas escolas particulares pagas, restando ainda as distribuídas nas escolas culturais de imigrantes ${ }^{6}$.

Analisar essa relação, e as necessárias mudanças para a democratização da educação no Chile, passa pela correlação de forças apresentadas pela sociedade chilena, como foi o movimento estudantil, que apresentaremos abaixo, mas também pelas leis que regem a educação e que perduraram durante algum tempo após o fim da ditadura. Pretendemos apresentar algumas dessas leis, além da organização do Sistema Nacional de Educação.

Iniciaremos pelo Ministério da Educação (Mineduc), órgão responsável pelas políticas de educação, que, juntamente com o Conselho Nacional de Educação (CONED), a Agência da Qualidade da Educação e a Superintendência da Educação, são responsáveis pela administração do referido Sistema, conforme consta no artigo 6o da Lei Geral da Educação (LGE). o CONED consulta especialistas das universidades e de grupos externos para formular a política de educação e de controle da qualidade. 0 financiamento dessas consultas se dá por meio de recurso público advindo do Fundo de Pesquisa e

\footnotetext{
${ }^{6}$ Segundo dados do Mineduc. Disponível em: http://junarsemantics.s3.amazonaws.com/mineduc/BigData/Visualizaciones/VZ1/dist/index.html. Acesso em: 22 jan. 2021.
} 


\section{JORNAL DE Políticas EducacionaIS}

ISSN 1981-1969

Desenvolvimento da Educação (FONID). Além desse fundo, há a Subvenção Escolar Preferencial, conforme lei específica.

A Lei 20.248/2008, Lei de Concessão Preferencial de Escolas, criou a Subvenção Educacional Preferencial (SEP), destinada a melhorar a qualidade da educação dos estabelecimentos educacionais subvencionados. É a SEP que regulamenta o outro tipo de serviço, a Assistência Técnica Educacional (ATE), pela qual o Estado legitima a entrada dos sujeitos privados nas instituições de ensino, para fornecer e aplicar apoio pedagógico, ao mesmo tempo que desmobiliza os municípios para essa oferta, pois eles não têm condições de concorrer com organizações privadas, que estão no mercado preparadas para desenvolver esse trabalho pedagógico.

Segundo Santa Cruz (2016), a necessidade de melhorar os resultados na prova estandardizada de 2000 levou o governo chileno a concluir que os programas compensatórios que faziam parte da reforma educacional colocada em pauta pelo Estado não estavam promovendo melhora. Foi, então, que o Estado "[...] começou a tirar todos os programas compensatórios, que haviam melhorado um pouco certas escolas, mas eram limitados, e passou a introduzir apoio às escolas, [sendo] que hoje no Chile todo o dinheiro de apoio à escola está privatizado" (SANTA CRUZ, 2016, entrevista, tradução nossa). Santa Cruz referia-se à Assistência Técnica Educacional (ATE), criada pela lei de 2008.

Outra lei importante, criada em 2009, foi a Lei Geral de Educação (LGE), que derrogou a Lei Orgânica Constitucional do Ensino (LOCE), ainda do período ditatorial e que vigeu por 19 anos, após o fim da ditadura.

A mobilização estudantil, em 2006 no Chile, foi a grande impulsionadora e estimuladora da sociedade para a discussão da nova lei da educação. Em 2006, os estudantes secundários fizeram uma mobilização massiva ocupando e paralisando 600 estabelecimentos de ensino em todo o país, por dois meses. Foi a conhecida "Revolta dos Pinguins"7. A LGE, considerada a correlação de forças do legislativo conservador, pouco favorável a mudanças mais radicais, como o fim do lucro e a seleção para ingresso dos

\footnotetext{
${ }^{7}$ Assim denominada pelo uniforme que usavam os estudantes: camisa branca e paletó preto.
} 


\section{JORNAL DE}

\section{Políticas Educacionals}

ISSN 1981-1969

alunos na escola, faz uma reforma na educação voltada para a fiscalização, a qualidade e a equidade, criando “[...] uma agência de qualidade da educação e [...] uma superintendência de educação. A primeira ficaria responsável por avaliar o desempenho de alunos e estabelecimentos; a segunda, por fiscalizar a atuação dos administradores de estabelecimentos” (MELLO, 2015, p. 126). A mesma lei legitima “[...] o principal instrumento de avaliação" da educação no Chile que "[...] é o Sistema de Medição da Qualidade da Educação (SIMCE), definido como padrão preferencial pela agência em 2012" (MELLO, 2015, p. 131).

Segundo Bellei (2016,), o sistema de avaliação de aprendizagem é um processo de estandardização que iniciou com a ditadura militar e perdura até os dias atuais. Seu resultado passou a ser publicizado, pelo Diário Oficial em 1994/95, sob a égide do governo democrático, para que as famílias conhecessem o ranking das escolas ao efetuar a escolha para matricular seus filhos, iniciando, dessa forma, a competição em torno do desempenho. Antes, a competição era pela matrícula, pelos recursos e pelo prestígio, dentre outros que não os resultados. Com o início da publicação dos resultados, todavia, a lógica é de um controle mais tecnocrático do desempenho (BELLEI, 2016, entrevista, tradução nossa). O Sistema de Medição da Qualidade da Educação (SINCE) (1988), ao avaliar os alunos, estimula a estandardização das escolas e a concorrência entre elas por matrículas. O Chile também institucionalizou os testes para os professores (2002) e gestores de escolas.

A mensuração da qualidade da educação por meio da avaliação de resultado final coloca a qualidade como uma "estratégia competitiva" ou como "um instrumento mensurável e com custo" (GENTILI, 1998, p. 127). No intuito de melhor explicitar o que defendemos como qualidade na educação, mesmo que sucintamente, por se tratar de um conceito polissêmico, trazemos autores que destacam as dimensões extra e intraescolares da qualidade da educação. Na dimensão extraescolar, os autores nomeiam “[...] as condições de vida das camadas sociais menos favorecidas e [menos] assistidas [devido] o nível de renda, a escolarização dos pais e seus hábitos de leitura, o acesso aos bens culturais [...]", dentre outros (DOURADO; OLIVEIRA; SANTOS, 2007, p. 14) 


\section{JORNAL DE}

\section{Políticas Educacionals}

ISSN 1981-1969

Assim, a partir da conceituação de avaliação aqui explicitada, há que se questionar a medição da qualidade da educação chilena, que não pode ignorar as condições extraescolares de um grande número de alunos oriundos de famílias empobrecidas pela grande concentração de renda por uma diminuta e privilegiada parcela de sua população, originada pelo modelo econômico neoliberal existente no Chile há mais de 40 anos.

Ainda, segundo Gentili (1998), os critérios de qualidade "[...] assumidos pelos setores de esquerda" devem ser aqueles compatíveis com a "democratização radical da educação" e o "fortalecimento progressivo da escola pública" (GENTILI, 1998, p. 130), critérios que estão diretamente ligados ao conceito de democracia assumido por nós no início deste texto.

Em continuidade à explicitação do aparato legal que rege a educação no Chile, citamos a Lei 20.501 de 2011, que retirou das mãos do prefeito a escolha dos dirigentes municipais de escolas, criando um novo mecanismo para selecionar diretores com o objetivo de melhorar a gestão e administração da educação pública e fortalecer o desempenho gerencial da gestão escolar, funcional ao sistema educacional chileno e à lógica empresarial da educação.

A Lei 20.845/15, Lei de Inclusão Escolar, é de suma importância pelos avanços que consegue institucionalizar, colocando fim ao lucro e ao copago, de forma gradual, seguida da Lei 21.091/2018, que concede a gratuidade da educação superior para a parcela mais vulnerável da sociedade chilena. Todos os avanços no aparato de regulação da educação são resultantes de pressões populares, como resposta a uma agenda social imposta pela organização e manifestações dos estudantes chilenos.

\section{Sujeitos Privados que atuam na Educação Pública Chilena}

Para a análise das múltiplas formas de relação entre o público e o privado na educação chilena, é preciso considerar como pano de fundo a redefinição do papel do Estado e as consequências de sua subjugação às lógicas empresariais na gestão educacional. No Chile, a existência de uma legislação permissiva a concessões ao setor 


\title{
JORNAL DE Políticas Educacionals
}

ISSN 1981-1969

privado e o aporte substancial de financiamento pelo poder público são fatores que determinam a configuração das políticas públicas na área da educação. Tal estruturação permite questionar como são feitos os investimentos e a quem interessam as subvenções do Estado.

0 modelo de política educacional chilena também se revela na influência de organismos internacionais, uma vez que muitas das práticas educativas do país se alinham aos ditames desses organismos aos quais está vinculado ${ }^{8}$. 0 Chile é membro da Organização para a Cooperação e Desenvolvimento Econômico (OCDE) desde 2010. Trata-se de um grupo de mais de 30 países, considerados economicamente ricos, que estabelece diretrizes para a política educacional de seus membros. A OCDE estimula as parcerias público-privadas na educação:

\begin{abstract}
Por meio da aprendizagem baseada no trabalho, os alunos adquirem as habilidades que são valorizadas no local de trabalho. Esta aprendizagem também é uma forma de desenvolver parcerias público-privadas e de envolver parceiros sociais e empregadores no desenvolvimento de programas de VET (Programas de educação e treinamento vocacional), muitas vezes definindo estruturas curriculares (OCDE, 2019, p. 09, tradução nossa).
\end{abstract}

O excerto foi coletado do documento Education at a Glance/2019, que faz alusão a um modelo social que relaciona educação e desenvolvimento econômico e cujas avaliações servem de referência ao Ministério da Educação do Chile ${ }^{9}$. Nessa direção, outros órgãos internacionais também exercem influência na política de educação do país, dentre os quais: o Banco Mundial (BM), a Organização das Nações Unidas (ONU) e o Programa de Promoção da Reforma Educativa da América Latina e do Caribe (PREAL).

Para além dos organismos internacionais atuando no Chile, há instituições privadas operando em parceria com o Sistema Nacional de Educação, mais

\footnotetext{
8 É o caso, por exemplo, do modelo de provas padronizadas promovido pelo Programa Internacional de Avaliação de Estudantes (PISA), da OCDE.

${ }^{9}$ Disponível em: https://bibliotecadigital.mineduc.cl/handle/20.500.12365/14428. Acesso em: 16 jan. 2021.
} 


\section{JORNAL DE Políticas Educacionals}

ISSN 1981-1969

especificamente junto ao CONED, definindo a política educacional por meio de um currículo nacional obrigatório para todas as escolas, públicas ou privadas, o qual define o conteúdo dos Planos Curriculares e as avaliações estandardizadas. O CONED oferece vários modelos de planos de estudo que podem ser adotados pelas escolas, prática que acontece principalmente com as escolas públicas. Segundo Bellei (2016), algumas escolas privadas têm seus próprios planos, sobretudo as escolas vinculadas a corporações religiosas, que, no entanto, precisam ser aprovados pelo Ministério da Educação (BELLEI, 2016, entrevista, tradução nossa).

No campo da assistência técnica às escolas, ressalta-se a atuação da Fundación Educación 2020, organização da sociedade civil criada em 2008 pelo engenheiro e professor universitário Mario Waissbluth. Originou-se de um manifesto com propostas para melhorar a educação chilena até 2020, por isso o ano de 2020 consta em sua denominação ${ }^{10}$.

A Educación 2020 é a única representante chilena da Rede Latino-americana de Organizações da Sociedade Civil para a Educação (REDUCA) e segue o propósito geral do grupo, isto é, "promover políticas públicas para melhorar a qualidade e igualdade da educação"11. A fundação se mostra atenta, também, às peculiaridades da educação chilena, dado que procura defender um modelo de educação pública aberto ao setor privado: “É imprescindível não só preservar o que existe, mas também recuperar a qualidade do sistema público, para que ele coexista com o privado em estado de 'competição equilibrada"' (WAISSBLUTH, 2014, p. 48, tradução nossa).

A Fundação Educación 2020 trabalha nas escolas do Chile desde 2014. Conforme consta em seu website, a organização atua em cerca de 96 escolas e liceus e tem mais de 2000 estudantes distribuídos em 4 regiões e 22 comunas do país. Uma de suas principais propostas é o programa Experiência Empresa, desenvolvido junto com a Fundação Itaú, que se propõe a ser uma ponte entre o mundo empresarial e a educação técnica profissional. Em 2017, a Educación 2020 criou um plano nacional com 30 propostas para

\footnotetext{
${ }^{10}$ Disponível em: https://www.mariowaissbluth.com/descargas/momento0.pdf. Acesso em: 17 jan. 2021.

${ }^{11}$ Disponível em: https://www.reduca-al.net/pt/nosotros. Acesso em: 17 jan. 2021.
} 


\section{JORNAL DE}

\section{Políticas EducacionaIS \\ ISSN 1981-1969}

mudar a qualidade da educação do país até 2030, em conjunto com outros organismos.

Sua atuação não se limita somente a dar assistência às escolas, já que possui outras atividades como pesquisas e acompanhamento de projetos de leis educacionais por meio do Observatório Legislativo. Salientamos, também, a prática de lobby junto ao Parlamento, com visitas às comissões para apresentar as ideias da fundação ${ }^{12}$.

Existem muitos sujeitos semelhantes à Educación 2020 que, junto a outros tipos de organizações, formam uma rede de relações organizada para atuar no sistema de educação chileno. A figura abaixo ilustra alguns dos sujeitos privados que, de algum modo, atuaram ou atuam na educação do Chile ${ }^{13}$.

Figura 1: Principais sujeitos que atuam na educação do Chile

12 Disponível em: http://educacion2020.cl/innovacion-educativa/. Acesso em: 21 abr. 2020.

${ }^{13} \mathrm{Na}$ figura, constam como exemplos de sujeitos individuais os seguintes nomes: Ana Maria Raad, diretora da plataforma digital Educarchile e da Aprendo en Casa; Raul Figueroa Salas, diretor-executivo da Fundación Acción Educar e atual ministro da educação do Chile; e Sebastian Piñera, fundador da Fundación Futuro e atual presidente do Chile. 


\section{JORNAL DE POLÍTICAS EDUCACIONAIS ISSN 1981-1969}

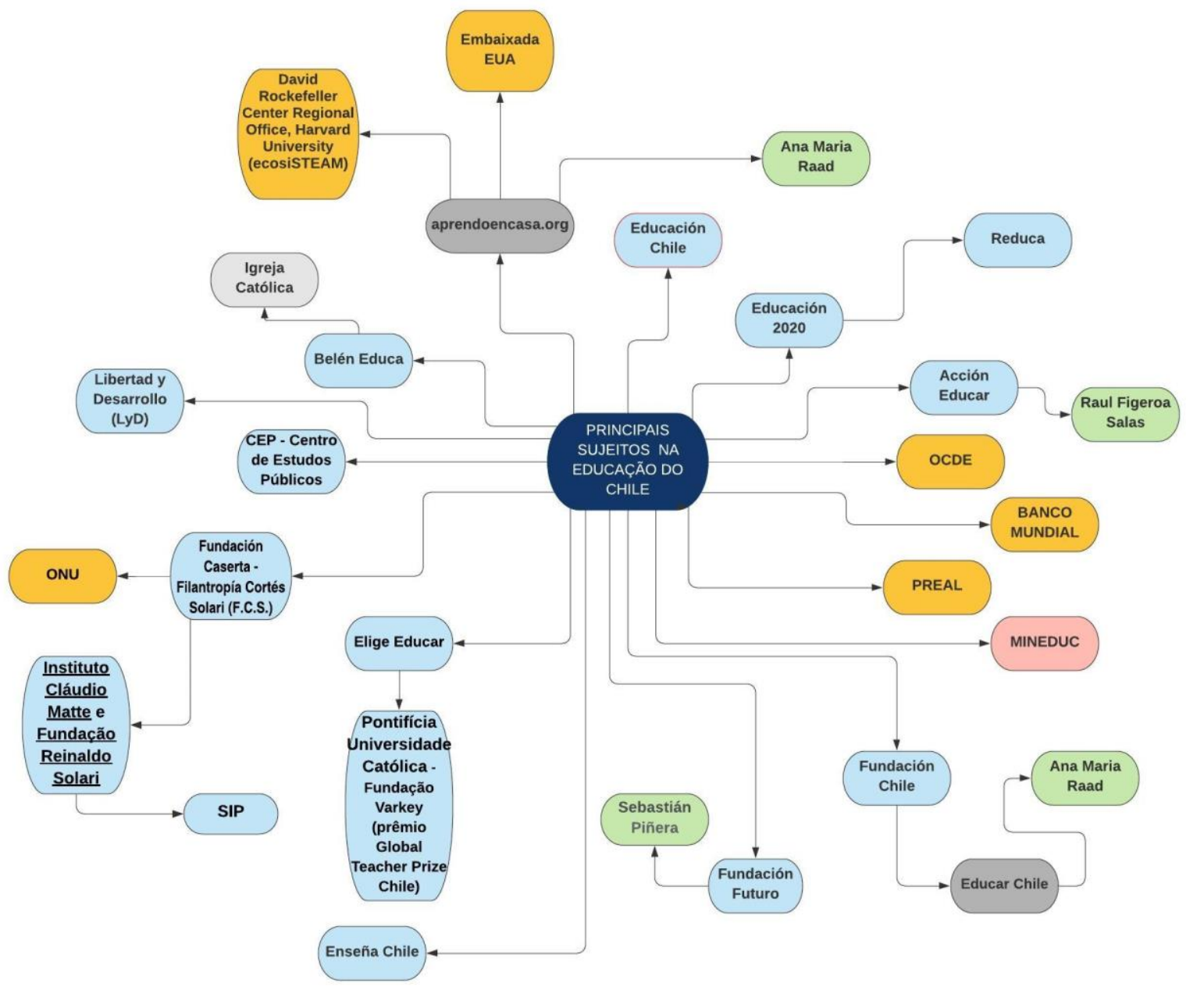

Fonte: Figura produzida pelas autoras para relatório da pesquisa GPRPPE/2020 (em elaboração)

Os sujeitos apontados são diferentes entre si, mas todos compartilham a intenção de intervir na educação pública. Há sujeitos coletivos, individuais, nacionais e internacionais e existem também aqueles que atuam por meio de plataformas digitais, como a Aprendo en Casa ${ }^{14}$, plataforma que surgiu em 2020, durante a Pandemia do coronavírus (COVID-19). Ela possui conteúdo digital para ensino a distância e faz parte

\footnotetext{
${ }^{14}$ Não confundir com o programa público Aprendo en casa, do Peru, que compreende um serviço de ensino a distância para televisão, rádio e Internet, dedicado à educação básica durante o estado emergencial causado pela COVID-19 (Resolução Ministerial no 160-2020-MINEDU). Disponível em: http://www.gob.pe/institucion/minedu/campa\%C3\%B1as/914-aprendo-en-casa. Acesso em: 13 jan. 2021.
} 


\section{JORNAL DE} Políticas EducacionaIS

ISSN 1981-1969

de uma rede colaborativa que aproxima organizações da América Latina ligadas à educação, como a Educación 2020, a Mexicanos Primero, a Fundación Caserta, dentre outras. A ideia é apoiada pelo programa ecosiSTEAM, iniciativa desenvolvida pelo escritório regional Harvard Chile DRCLAS ${ }^{15}$, por intermédio de Ana Maria Raad, que atuou anteriormente na ONG brasileira Comitê para Democratização da Informática (CDI) ${ }^{16}$.

A Aprendo en Casa faz parte da Rede Latino-Americana de Portais Educacionais (RELPE), que conta com 19 países da América Latina. A circulação dos conteúdos entre os participantes é possibilitada pelo uso de uma tecnologia que compartilha as publicações, ferramenta desenvolvida pela Fundación Chile (JORDUA; KLIMA, 2017, p. 108). Para que isso fosse possível, houve aprovação pelo governo chileno de um projeto concedido à Fundación Chile, com contribuição do Fondo de Fomento al Desarrollo Científico y Tecnológico (FONDEF), no valor de $\$ 108$ milhões de pesos chilenos ${ }^{17}$.

A Fundación Chile é uma organização privada que atua em parceria com o governo chileno, segundo consta em seu website ${ }^{18}$. Foi criada em 1976, durante a ditadura, não possui fins lucrativos e trabalha com inovação tecnológica em várias áreas. Na educação, produziu, ao lado do Mineduc, a plataforma digital Educarchile. É também uma das parceiras da Red de Escuelas Líderes (REL), que, atualmente, reúne 110 escolas entre Arica e Punta Arenas ${ }^{19}$.

Ainda sobre os sujeitos da Figura 1, destaca-se o Centro de Estudos Públicos (CEP), uma das mais tradicionais instituições privadas, que atua como think tank. Foi criada no período ditatorial, em 1980, e tem natureza jurídica de fundação sem fins lucrativos. 0 seu financiamento se dá pela contribuição de instituições privadas como, por exemplo, o Banco Itaú Corpbanca, o Banco de Chile e a Larraín Vial S.A. Corretores de Bolsa ${ }^{20}$. Ao seu lado, há outra instituição com forte atuação como think tank, a Libertad y Desarrollo

\footnotetext{
15 Disponível em: https://www.aprendoencasa.org/pais/chile/. Acesso em: 11 jan. 2021.

16 Disponível em: https://fch.cl/equipo/ana-maria-raad/. Acesso em: 11 jan. 2021.

17 Disponível em: https://www.conicyt.cl/fondef/lineas-de-programa/instrumentos-pasados/ticedu/resultados/. Acesso em: 13 jan. 2021.

18 Disponível em: https://fch.cl/sobre-fch/. Acesso em: 15 jan. 2021.

${ }^{19}$ Disponível em: https://cutt.ly/ukqerhv. Acesso em: 13 jan. 2021.

${ }^{20}$ Disponível em: https://www.cepchile.cl/. Acesso em: 18 jan. 2021.
} 


\section{JORNAL DE} Políticas EducacionaIS

ISSN 1981-1969

(LyD), fundada em $1990^{21}$. Ambas se autodenominam como produtoras de conhecimento de temas de interesse público. Sobre o conceito de think tanks, Mendes e Peroni (2020, p. 1) esclarecem que "Os think tanks são organizações que existem desde o século XIX e atuam como formuladoras de ideias e opiniões, produtoras de conhecimento e influenciadoras de políticas públicas nas mais diversas áreas de atuação".

Mencionamos, ainda, a Educación Chile, instituição privada que trabalha principalmente com cursos para professores e consultorias para as escolas ${ }^{22}$, e a Belén Educa, que se caracteriza como filantrópica e católica ${ }^{23}$. Como exemplo de instituição filantrópica temos, também, a Fundación Caserta, pertencente ao grupo Filantropía Cortés Solari (F.C.S.), que está ligado ao empresário Reinaldo Solari24, o qual é proprietário da Fundação Reinaldo Solari. Esta fundação, por sua vez, ajudou a criar a Aptus Chile, empresa privada, sem fins lucrativos, que atua em colégios com desempenho ruim no SIMCE e que se autodenomina "potenciadora educacional"25. Ela atua em parceria com a Rede de Colégios SIP, empresa privada, sem fins lucrativos, que reúne vários estabelecimentos de ensino fundamental no Chile. Chama-se SIP porque se originou da antiga Sociedade de Instrução Primária de Santiago, datada de $1856^{26}$.

Como se vê, há uma profusão de sujeitos atuando em rede na educação chilena, e todos possuem como principal fonte de renda subsídios oriundos do poder público. Há um estudo feito pela Sociedad en Acción - grupo privado ligado ao Centro de Políticas Públicas da Universidade Católica do Chile e da Fundación Chile + Hoy - que explicita tal situação ao afirmar que os subsídios públicos atingem $45 \%$ da receita das instituições não governamentais ${ }^{27}$.

A atuação da iniciativa privada nos espaços públicos está ancorada no discurso da qualificação da educação, porém, essa discussão “[...] está descontextualizada da realidade

\footnotetext{
${ }^{21}$ Disponível em: https://lyd.org/. Acesso em: 18 jan. 2021.

22 Disponível em: https://www.educacionchile.cl. Acesso em: 18 jan. 2021.

${ }^{23}$ Disponível em: http://www.beleneduca.cl/. Acesso em: 18 jan. 2021.

${ }^{24}$ Disponível em: https://www.caserta.cl/. Acesso em: 18 jan. 2021.

25 Disponível em: https://www.aptus.org/. Acesso em: 18 jan. 2021.

${ }^{26}$ Disponível em: https://www.sip.cl/about/que-es-sip-red-de-colegios/. Acesso em: 18 jan. 2021.

${ }^{27}$ Disponível em: https://bityli.com/GzyKd, p. 6, tradução nossa). Acesso em: 11 jan. 2021.
} 


\section{JORNAL DE}

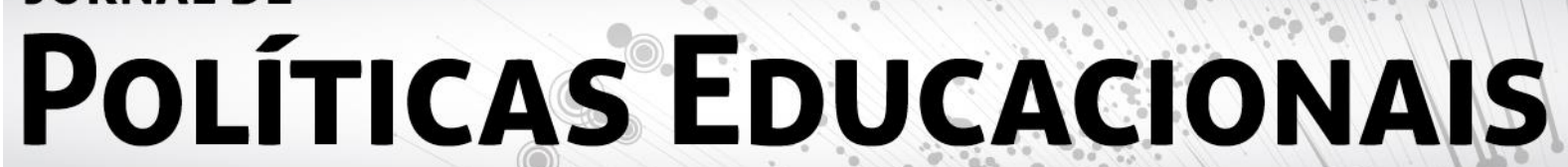

ISSN 1981-1969

social, política e econômica que rege as relações dos sujeitos na perspectiva da superação da exclusão presente na sociedade capitalista" (XXXXX, 2009, p. 140).

Para Rikowski (2017, 398), as “[...] circunstâncias desesperadas para o capital global", referindo-se à "Grande Recessão de 2007-09 e a Grande Depressão que veio em seguida”, justificam a razão pela qual “o financiamento estatal da educação aparece como uma fonte tentadora para sugar dinheiro público".

A educação não pode ser vista ou negociada como mercadoria, pois se trata de um direito que precisa ser assegurado por meio de políticas públicas, universais e de qualidade.

\section{Considerações Finais}

O Sistema de educação chileno expandiu as escolas privadas por meio de financiamento público. Se por um lado, promoveu melhora na universalização do acesso à educação, por outro aprofundou um quadro de segregação escolar. Pelas práticas de estandardização e de competição, acabou por instituir escolas para os filhos de famílias ricas e escolas para os filhos de famílias pobres.

A educação no Chile está estruturada em classes e há distintas escolas para distintos sujeitos. Famílias que disponibilizam de cinco mil pesos podem pagar uma escola privada bem colocada no ranking do sistema de avaliação em larga escala. Os governos democráticos mantiveram a estrutura de mercado na educação, aperfeiçoando alguns mecanismos que aprofundaram a competição! A publicação do resultado das avaliações no Diário Oficial do país é uma delas, pois atende ao mercado criando um ranking que orienta a escolha dos pais pelas escolas, ao mesmo tempo que estimula a competição entre elas.

Mesmo com a abertura política no Chile, o Estado não assumiu a definição da educação no país, como inicialmente nos pareceu, uma vez que o marco curricular geral, que determina o conteúdo das diferentes disciplinas da educação e o conteúdo da avaliação (SIMCE), é definido/aprovado pelo CONED. O Ministério da Educação, ao qual 


\section{JORNAL DE}

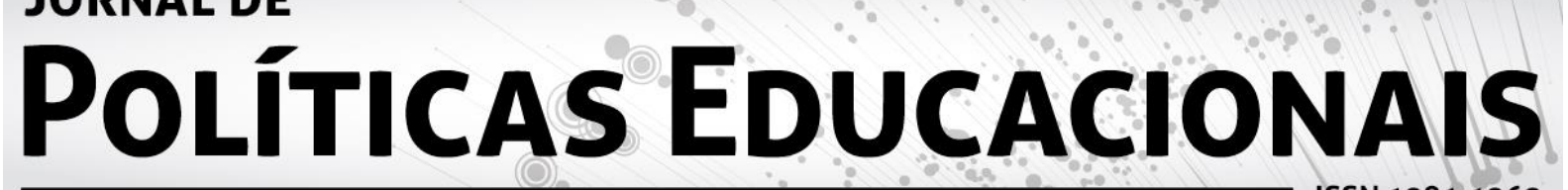

ISSN 1981-1969

está ligado o Conselho, tem como parceiros, nessa definição, instituições privadas como Educación 2020; Ensiña Chile; El Plan Maestro, Elige Educar e Fundación Futuro, instituição que foi presidida por Sebastián Piñera até assumir a Presidência do Chile, sendo substituído por sua filha, Magdalena Piñera Morel.

Portanto, as instituições privadas participam direta ou indiretamente na educação chilena, isto é, atuam dentro das escolas por meio do Atendimento Técnico Especializado e também no âmbito das decisões políticas, sendo que o debate da importância da educação pública é preterido. Verificamos, em nossa pesquisa, a presença cada vez maior do privado mercantil definindo o conteúdo da educação pública, no Chile e na América Latina.

É importante destacar que as instituições privadas que atuam na educação no Chile fazem parte de uma rede de instituições com atuação global. Essa atuação ocupa um aspecto muito importante no processo de definição do conteúdo da educação, e no arrebatamento de consideráveis recursos públicos, tanto quanto esvazia o processo de participação social.

Considerando que a educação desempenha um papel fundamental e imprescindível na democratização da sociedade, a sua função social não é compatível com a de uma sociedade de mercado, que trata a educação como uma mercadoria adquirida por quem pode pagar, o que faz com que o cidadão de direito deixe de existir para dar lugar ao cidadão cliente. Assim, perde-se a concepção de educação como direito público, social e universal.

\section{Referências}

AHUMADA, Miguel. Una revisión socialista a la crítica (neoliberal) al neoliberalismo. Heterodoxia, 08 fev. 2020. Disponível em: http://www.heterodoxia.cl/una-revisionsocialista-a-la-critica-neoliberal-al-neoliberalismo/. Acesso em: 01 nov. 2020.

BELLEI, Cristian. El gran experimento: Mercado y privatización de la educacion chilena. Santiago: LOM ediciones, 2015. 


\section{JORNAL DE Políticas Educacionals}

ISSN 1981-1969

CHILE. Ley 18.962/1990. Ley Orgânica Constitucional do Ensino/LOCE. Diario Oficial de la República de Chile, Santiago, 1990. Disponível em:

https://www.bcn.cl/leychile/navegar?idNorma=30330. Acesso em: 17 jan. 2021.

CHILE. Ley 20.248/2008. Ley de Subvención Escolar Preferencial. Diario Oficial de la República de Chile, Santiago, 2008. Disponível em:

https://www.bcn.cl/leychile/navegar?idNorma=269001. Acesso em: 17 jan. 2021.

CHILE. Ley 20.370/2009. Ley General de Educación/LGE. Diario Oficial de la

República de Chile, Santiago, 2009. Disponível em:

https://www.bcn.cl/leychile/navegar?idNorma=1006043. Acesso em: 17 jan. 2021.

CHILE. Ley 20501/2011. Calidad Y Equidad de la Educación. Diario Oficial de la

República de Chile, Santiago, 2011. Disponível em:

https://www.bcn.cl/leychile/navegar?idNorma=1022346. Acesso em: 17 jan. 2021.

CHILE. Ley 20.845/2015. Ley de Inclusión Escolar. Diario Oficial de la República de Chile, Santiago, 2015. Disponível em:

https://www.bcn.cl/leychile/navegar?idNorma=1078172. Acesso em: 17 jan. 2021.

CHILE. Ley 21.091/2018. Ley sobre Educación Superior. Diario Oficial de la República de Chile, Santiago, 2018. Disponível em:

https://www.bcn.cl/leychile/navegar?idNorma=1118991. Acesso em: 17 jan. 2021.

CHILE. Ministerio de Educación. Sistema de Registro y Certificación de Entidades de Asistencia Técnica Educativa (ATE). 2020. Disponível em:

https://registroycertificacionate.mineduc.cl/. Acesso em: 09 jan. 2021.

DOURADO, Luiz Fernando; OLIVEIRA, João Ferreira; SANTOS, Catarina de Almeida. A qualidade da educação: conceitos e definições. Brasília: Instituto Nacional de Estudos e Pesquisas Educacionais Anísio Teixeira, 2007.

GENTILI, Pablo Antonio Amadeo. 0 discurso da "qualidade" como nova retórica conservadora no campo educacional. In: GENTILI, Pablo A. A.; SILVA, Tomaz Tadeu da (Org.). Neoliberalismo, Qualidade Total e Educação: visões críticas. 6. ed. Petrópolis: Vozes, 1998. p. 127-140.

JORDUA, Joaquín; KLIMA, Francisco. La Fundación Chile en el tiempo: Historia, trayectoria e impacto. Santiago: Fundación Chile, 2017. Disponível em:

https://fch.cl/wp-content/uploads/2019/09/fundacion_chile-en_el_tiempo.pdf. Acesso em: 13 jan. 2021.

MELLO, Eduardo Brigidi. Chile: a experiência do estado subsidiário. In: PICCHETTI, Vanessa (Org.). Educação Básica e Ensino Médio \#11. Coleção Mundo Afora. Brasília: Ministério das Relações Exteriores/Itamaraty, 2015.

MENDES, Valdelaine da Rosa; PERONI, Vera Maria Vidal. Estado, mercado e formas de privatização: a influência dos think tanks na política educacional brasileira. Revista Espaço Pedagógico, Passo Fundo, v. 27, n. 1, p. 65-88, 1 fev. 2020 


\section{JORNAL DE Políticas EducacionaIS}

ISSN 1981-1969

MÉSZÁROS, István. Para além do Capital. São Paulo: Boitempo Editorial; Campinas: Editora da UNICAMP, 2002.

OCDE. Organização para a Cooperação e Desenvolvimento Econômico. Education at a Glance 2019: OECD Indicators. Paris, 2019. Disponível em: https://www.oecdilibrary.org/education/education-at-a-glance-2019_f8d7880d-en. Acesso em: 09 jan. 2021.

ORELLANA, Victor. Sobre el nuevo pueblo chileno: esperanzas y desafíos presentes.

Fundación Nodo XXI, Santiago, 02 nov. 2019. Disponível em:

https://www.nodoxxi.cl/noticias/2019/un-nuevo-pueblo-nace-en-chile/. Acesso em: 20 nov. 2019.

RIKOWSKI, Gleen. Privatização da Educação E formas de mercadoria. Revista Retratos da Escola, Brasília, n. 21, p. 393-413, 2017.

RUIZ, Carlos; BOCCARDO, Giorgio. Los Chilenos bajo el neoliberalismo. Clases y conflicto social. Fundación Nodo XXI, Santiago, 2014. Disponível em:

https://www.nodoxxi.cl/publicaciones/los-chilenos-bajo-el-neoliberalismo-clases-yconflicto-social/. Acesso em: 20 nov. 2019.

XXXXX. 2009.

VANNI, Xavier Cucurella. Evolución de las políticas educacionales en Chile: 1980-2014. In: BELLEI, Cristian (Org.). El gran experimento: Mercado y privatización de la educación chilena. Santiago: LOM ediciones, 2015. p. 23-45.

VIEIRA, Evaldo. As políticas sociais e os direitos sociais no Brasil. Serviço Social \& Sociedade, São Paulo, p. 67-73, 1998.

WAISSBLUTH, Mario. La educasion en Chile esta vien. 3. ed. Santiago, 2014. Disponível em:

http://educacion2020.cl/sites/default/files/mario_waissbluth_la_educasion_esta_vien.p df. Acesso em: 10 jan. 2021.

WOOD, Ellen Meiksins. Democracia contra o capitalismo: a renovação do materialismo histórico. São Paulo: Boitempo Editorial, 2003. 


\section{JORNAL DE Políticas Educacionais \\ ISSN 1981-1969 \\ Volume 15 \\ Número 40 \\ 26 de agosto de 2021}

(c)

SORERTIGHISRESERNED O Copyright é retido pelo/a autor/a (ou primeiro co-autor) que outorga o direito da primeira publicação ao Jornal de Políticas Educacionais. Mais informação da licença de Creative Commons encontram-se em https://creativecommons.org/licenses/by-nc-nd/4.0. Qualquer outro uso deve ser aprovado em conjunto pelo/s autor/es e pelo periódico.

JoRnal DE Políticas EduCACionaIs é uma publicação do Núcleo de Políticas Educacionais do Setor de Educação da Universidade Federal do Paraná - NuPE/UFPR, em consórcio com a Linha de Pesquisa em Políticas Educacionais do Programa de Pós-Graduação em Educação - PPGE/UFPR, que aceita colaboração, reservando-se o direito de publicar ou não o material espontaneamente enviado à redação. As colaborações devem ser enviadas ao NuPE/UFPR, conforme orientações contidas nas páginas do periódico na internet: http://revistas.ufpr.br/jpe.

\section{INDEXAÇÃO:}

BASE DE DADOS
Sumário.Org
Google Scholar
BASE
Dimensions
Miar

DIRETÓRIOS
Scielo Educ@
Diadorim
DOAJ
Erih Plus
Latindex
EZB
ROAD
Journal 4-free

ÍNDICES
Index Copernicus
Cite Factor
PORTAIS
LiVre
Capes
Science Open
World Wide Science

(Periódico integralmente disponível apenas em via eletrônica)

Jornal de Políticas Educacionais / Núcleo de Políticas Educacionais da Universidade Federal do Paraná -

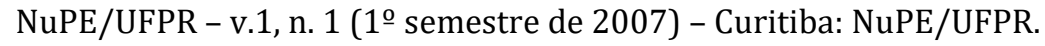

Volume 15, número 40 - Agosto de 2021

ISSN 1981-1969

1. Educação - Periódicos. 2. Política Educacional - Periódicos. I. NuPE/UFPR 


\section{JORNAL DE Políticas Educacionals}

Comitê Editorial:

Elisângela Scaff (UFPR)

Daniela de Oliveira Pires (UFPR)

Conselho Editorial:

Adriana Aparecida Dragone Silveira (UFPR-Brasil), Ana Lorena de Oliveira Bruel (UFPR-Brasil), Andréa Barbosa Gouveia (UFPR - Brasil), Angela Maria Martins (FCC, Brasil), Angelo Ricardo de Souza (UFPRBrasil), Antonia Almeida Silva (UEFS, Brasil), Cassia Alessandra Domiciano (UFPR-Brasil), Cesar Tello (Universidad Nacional Tres Febrero, Argentina), Claudia Regina Baukat Silveira Moreira (UFPR-Brasil), Cristiane Machado (Unicamp- Brasil), Elton Luiz Nardi (UNOESC, Brasil), Fernanda Saforcada (Universidad de Buenos Aires - UBA - Argentina), Isaac Paxe (Instituto Superior de Ciências da Educação (ISCED- Luanda, Angola), Gabriela Schneider (UFPR-Brasil), Gladys Beatriz Barreyro (USP - Brasil), Gilda Cardoso Araújo (UFES - Brasil), Gustavo Enrique Fischman (Arizona State University - USA), Janete Maria Lins de Azevedo (UFPE, Brasil), Jefferson Mainardes (UEPG - Brasil), João Ferreira de Oliveira (UFG - Brasil), Jorge Alarcon Leiva (Universidad de Talca - Chile), Jorge Manuel Gorostiaga (UNSAM - Argentina), Juca Gil (UFRGS Brasil), Luciana Rosa Marques (UFPE, Brasil), Marcos Alexandre dos Santos Ferraz (UFPR-Brasil) Marcia Aparecida Jacomini (Unifesp-Brasil), Maria Dilnéia Espíndola Fernandes (UFMS, Brasil), Natalia Oliveira Woolley (UCLA, USA), Ney Cristina Monteiro de Oliveira (UFPA - Brasil), Nicolás Bentancur, (Universidad de la República de Uruguay), Nora Krawczyk (Unicamp- Brasil), Pedro Flores-Crespo (UAQ México) Rodrigo da Silva Pereira (UFBA, Brasil), Robert Verhine (UFBA - Brasil), Rosana Cruz (UFPI - Brasil), Rubens Barbosa Camargo (USP - Brasil), Sebastián Donoso Díaz (Universidad de Talca - Chile), Theresa Adrião (UNICAMP Brasil), Vera Maria Vidal Peroni (UFRGS - Brasil).

Créditos e Agradecimentos:

Revisão de Língua Portuguesa, Abstract e Resumen: Programa de apoio às publicações científicas periódicas da UFPR

Arte e diagramação: Tiago Tavares (tiagotav@gmail.com)

Jornal de Políticas Educacionais

Universidade Federal do Paraná

Setor de Educação

Núcleo de Políticas Educacionais - NuPE/UFPR

Avenida Sete de Setembro, 2645

$2^{\circ}$ andar, Sala 213

80.230-010 - Curitiba - PR - Brasil

Tel.: 41-3535-6264

jpe@ufpr.br

http://revistas.ufpr.br/jpe 